\title{
O "som" como figura vocal e o "som" como signo: considerações a partir da dupla essência da linguagem
}

\author{
Aline Vargas Stawinski ${ }^{1}$
}

\section{Resumo}

Este artigo propõe-se a discutir, a partir do conjunto de manuscritos intitulado De la double essence du langage, a que se refere esta dupla essência reiterada pelo linguista Ferdinand de Saussure. Lançaremos mão, assim, da leitura da edição crítica organizada por Amacker (SAUSSURE, 2011), levantando os seguintes questionamentos: o que é essencial para que um sistema linguistico tenha existência? O dado material é relevante para a construção do fato linguístico? Qual a diferença entre considerar-se o "som" como figura vocal e o "som" como signo? Optou-se por partir das ocorrências de "figura vocal" no decorrer das considerações de Saussure a fim de compreender mais amplamente o papel da figura vocal e sua relação com o conceito de forma. A problematização destas noções oportuniza a reflexão acerca do laço indissolúvel entre forma e sentido nos estudos saussurianos, assim como realca o importante papel do aspecto material vinculado a sua função significante.

Palavras-chave: Figura vocal. Signo. Forma. Dupla essência

\footnotetext{
${ }^{1}$ Mestra e doutoranda em Estudos da Linguagem com ênfase em análises textuais, discursivas e enunciativas (PPG Letras/UFRGS).
} 


\section{Considerações iniciais}

Os estudos saussurianos estão longe de cessar de exercer seus efeitos sobre os pesquisadores da linguagem. Seja para seguir, distanciar ou ultrapassar, as influências das reflexões do linguista genebrino parecem cada vez menos fadadas ao esquecimento: mais de um século após a sua morte, Ferdinand de Saussure continua a instigar pesquisadores, os quais debruçam-se sobre preciosos manuscritos, relegados hoje às bibliotecas universitárias de Genebra e de Harvard. O Curso de linguística geral, como é possível observar, para além de marco histórico no que é considerada a fundação da linguística moderna, apresenta-se também como "apenas" a nuance de uma busca incansável sobre a natureza da língua.

Edições de anotações, cadernos de alunos, cartas, preparações de conferências e aulas: tão vasto e tão diverso é o acervo que hoje é o legado material do linguista genebrino. Apesar de não ter se aventurado em muitas publicações em vida, Saussure influenciou e ainda influencia gerações de pesquisadores, que continuam a inquietar-se com o esplêndido objeto que é a língua.

Após a edição do Curso, que serviu para divulgar as reflexões de seus célebres cursos, veio a público também a famosa edição de Escritos de Linguística Geral. Esta publicação operou um papel bastante importante na divulgação de um pensamento mais complexo e em vias de construção de Saussure, que estava às voltas com a própria definição do objeto da linguística e, por consequência, precisava estabelecer as bases para que sua empreitada fosse possível.

Atualmente, há inúmeras publicações a respeito dos manuscritos deixados por Saussure. Para os leitores especializados, faz-se necessário cada vez mais um olhar atento para as fontes manuscritas e empreender leituras que por muito tempo ficaram fechadas em si mesmas. O material deixado pelo genebrino evoca questionamentos contemporâneos às problemáticas dos Estudos da Linguagem. Questões fundamentais que, longe de sanarem todas as dúvidas, amplificam nossos questionamentos e a curiosidade sobre o fenômeno da linguagem.

A primeira empreitada a partir dos manuscritos foi encabeçada por Robert Godel em Les sources manuscrites du Course de Linguistique Générale, de 1957. Posteriormente, Rudolf Engler publicou sua grande obra em dois tomos (1968-1974), a edição crítica do Curso, dando continuidade ao trabalho minucioso de Godel. Em 1967, Tullio de Mauro 
presenteia-nos com suas mais de trezentas notas em edição crítica do Curso. Alguns anos mais tarde, em 1978, Starobinski publica Les mots sous les mots a partir do achado de mais de 90 cadernos de Saussure dedicados aos estudos dos anagramas. Sob curadoria de Maria Pia Marchese, vão a público pela primeira vez, a partir de seu minucioso trabalho de edição, os manuscritos intitulados Phonétique (1995) e Théorie des sonantes (2002). Mais recentemente, também em 2002, é publicado o livro Écrits de linguistique générale, obra que reúne antigos documentos já editados por Rudolf Engler e novos documentos descobertos em 1996. Em 2011, Amacker organiza uma nova edição dos manuscritos pertencentes ao acervo BPU 1996 - edição crítica que contempla o manuscrito Arch. de Saussure $372^{2}$ e cujos critérios editoriais seguiram, majoritariamente, os adotados por Marchese nas obras referidas acima.

A empreitada de Amacker para uma nova edição é justificada na introdução à obra:

l'édition parisienne n'est pas une édition critique. Il y a donc place, notamment dans la collection du Cercle Ferdinand de Saussure, pour une publication scientifique qui soit plus proche des intentions de Rudolf Engler que les Écrits de linguistique générale; c'est précisément ce que je présente aujourd'hui au public spécialisé, en hommage à la mémoire de mon collègue et ami prématurément décédé (AMACKER, 2011, p. 11)3.

O pesquisador tece uma crítica, fazendo eco com Ludwig Jäger, à escolha do título dos Escritos de Linguística Geral, demasiadamente próximo de Curso de Linguística Geral (obra de autoria atribuída) - ou seja, duas obras de naturezas essencialmente distintas na medida em que o Curso é uma reconstrução a partir de notas de alunos enquanto que os Escritos se baseiam apenas em notas redigidas por Ferdinand de Saussure. A outra crítica refere-se à pretensa afirmação de que Saussure estaria preparando um livro sobre Linguística Geral. Jäger defende que Saussure organizou suas notas pessoais sob o título de "Science du Langage", referência mantida por Amacker na edição crítica do manuscrito.

\footnotetext{
2 "O texto propriamente dito do manuscrito Arch. de Saussure 372 é um conjunto de 271 folhas esparsas reunidas por R. Engler sob o título Escritos de linguística geral (segundo a notícia redigida pela BGE), conjunto constituído de dois blocos desiguais: 1 a 254 publicados (com omissões) e 255-274, ou seja, vinte 'folhas extraídas da massa de 'folhas esparsas' por R. Engler', anexados após a publicação dos Escritos de linguística geral” (Introduction em SAUSSURE, 2011, p. 18. Tradução livre).

3 “A edição parisiense não é uma edição crítica. Há lugar, portanto, especialmente na coleção do Círculo Ferdinand de Saussure, para uma publicação científica que seja mais próxima das intenções de Rudolf Engler do que os Escritos de Linguística Geral; é precisamente isso que eu apresento hoje ao público especializado, em homenagem à memória de meu colega e amigo que partiu prematuramente" (Tradução livre).
} 
Cabe assim ressaltar que a escolha da edição crítica de Science du langage - De la double essence du langage $e^{4}$ preparada por Amacker funda-se na natureza da sua publicação, que busca tornar os manuscritos mais acessíveis ao público especializado. Esta edição, em comparação com os Escritos, é mais restrita na medida em que não contempla os textos publicados por Engler em 1974. No entanto, a edição de Amacker oferece ao pesquisador acesso a notas marginais deixadas por Saussure, acréscimos, passagens primeiramente descartadas e reescritas - tudo devidamente descrito em notas. Ainda é possível encontrar, quando presentes, as referências às passagens da edição Gallimard, possibilitando ao leitor familiarizado com os Escritos encontrar as passagens com facilidade.

Amacker, na introdução à edição crítica (Introduction em SAUSSURE, 2011, p. 1718), destaca que De l'essence double $<$ du langage $>$ serve como título em um maior número de vezes; no entanto, De la double essence $<d u$ langage $>$ serve como título de um de seus mais completos manuscritos, sendo, por isso, escolhido como título na edição crítica. Neste artigo, nos questionamos: a que se refere a dupla essência abordada por Saussure? O que é essencial para que de fato exista um sistema linguístico? Qual a importância do dado material para a construção do fato linguístico? Com o intuito de tentar responder essas questões, optou-se por partir das ocorrências de "figura vocal" do decorrer de double essence a fim de compreender mais amplamente o papel da figura vocal e sua relação com o conceito de forma.

\section{O "som" como figura vocal e o "som" como signo}

Uma das questões recorrentes no conjunto de notas manuscritas que se reúnem sob o título da dupla essência da linguagem é a natureza da relação forma-sentido e as suas implicações para a delimitação das unidades da língua. Sendo assim, como interessa-nos particularmente a reflexão de Saussure sobre o aspecto material necessário à língua, observaremos as passagens em que o linguista lança mão da expressão "figura vocal" (figure

\footnotetext{
4 Science du langage constava como título de um envelope maior; dentro deste envelope encontravam-se outros, dentre eles um grande material sob o título De la double essence du langage, entre outras variações do mesmo título (AMACKER, 2011, p. 17).
} 
vocale). Antes de iniciarmos, porém, é necessário destacar algumas questões com relação à diferença entre "som" como tal e "som" como signo. Vejamos a passagem abaixo5:

Examinons si, dans la tranche horizontale, il existe une occasion quelconque où le son arrive comme tel - donc abstration faite de tout lambeau de sens attaché au son - à manifester une valeur (soit $a$ vis-à-vis des phénomènes de la langue propres à la tranche horizontale soit $b$ vis-àvis des dinstinctions nécessaires au linguiste pour la tranche horizontale). (SAUSSURE, 2011, p. 58) ${ }^{6}$

O que podemos compreender com a expressão "som como tal"? Conforme veremos no decorrer da nossa exposição, Saussure, em diversas passagens, aponta a relevância de diferenciar o que seria a "figura vocal" por si só da "forma", inseparável do sentido: "Il est faux (et impraticable) d'opposer la forme et le sens. Ce qui est juste en revanche c'est d'opposer la figure vocale d'une part, et la forme-sens de l'autre"7 (SAUSSURE, 2011, p. 72). Partindo desta consideração, entendemos que o "som como tal" refere-se à materialidade linguística (no caso, a materialidade sonora das línguas orais ${ }^{8}$ ); em oposição ao "som como tal" teremos o "som como signo" - ou seja, a unidade linguística, cuja existência depende da associação arbitrária e necessária entre o que, hoje, chamamos significante e significado. Sem tal associação não há signo - não há língua possível.

Sendo assim, é essencial reiterar: a figura vocal (o "som" como tal) só pode ser colocada em oposição à forma-sentido (o "som" como signo). Só existe linguisticamente a forma associada a um sentido, ou o sentido associado a uma forma: Il existe dans la langue: - $1^{\circ}$ si on la prend à un moment donné: non pas seulement des signes, mais aussi des

\footnotetext{
${ }^{5} \mathrm{Na}$ edição crítica de Amacker, o linguista, a fim de facilitar a busca e a comparação entre as fontes, referiu em cada uma das partes da Dupla essência a indicação correspondente à edição de Bouquet e Engler (SAUSSURE, 2002). Apesar de haver diferenças entre as duas edições, apontaremos em nota de rodapé os excertos correspondentes na edição dos Escritos (SAUSSURE, 2004) em tradução. Cabe ressaltar, porém, que não se trata de uma tradução propriamente dita.

6 "Examinemos se, na seção horizontal, existe alguma ocasião em que o som chegue, como tal (abstração feita de todo fragmento de sentido ligado ao som), a manifestar um valor - seja a) diante de fenômenos de língua próprios da seção horizontal, seja b) diante de distinções necessárias ao linguista para a seção horizontal" (SAUSSURE, 2004, p. 86).

7 “É errado (e impraticável) opor a forma e o sentido. O que é certo, em troca, é opor a figura vocal, de um lado, e a forma-sentido de outro" (SAUSSURE, 2004, p. 21).

${ }^{8}$ No caso das línguas de sinais, por exemplo, a materialidade não seria o "som", mas o "gesto". Em Frydrych (2013), discute-se o estatuto das línguas de sinais sob a ótica saussuriana: "o que importa no sinal não é o gesto em si, mas as diferenças quirêmicas, gestuais que permitem distinguir esse sinal de todos os outros, pois são elas que levam a significação" (FRYDRYCH, 2013, p. 76).
} 
significations non séparables des signes, vu que ceux-ci ne mériteraient plus leur nom sans signification (SAUSSURE, 2011, p. 79-80) ${ }^{9}$.

O que não existe na língua, conforme as anotações de Saussure, são

a) les significations, les idées, les catégories grammaticales hors de signes [...] b) les figures vocales qui servent de signes n'existent pas davantage dans la langue instantanée. Elles existent à ce moment pour le physicien, pour le physiologiste, non pour le linguiste, ni pour le sujet parlant. De même qu'il n'y a pas de signe hors de la signification (SAUSSURE, 2011, p. 80) ${ }^{10}$.

Assim, é reforçada mais uma vez a ideia de "figura vocal" como o ponto de vista do som que interessa ao fisiologista, e não ao linguista e tampouco ao sujeito falante, a final, o que importa a ambos é a potência de significar que a materialidade (sonora ou não) pode carregar. É o que ocorre quando se olha para a língua não a partir de um momento dado (ponto de vista sincrônico), mas através do tempo: "2o Si on prend la langue au contraire à travers une période: Alors il n'existe plus ni signe ni signification mais seulement des figures vocales" (SAUSSURE, 2011, p. 79-80) $)^{11}$.

Ao abordar a natureza do objeto em linguística, Saussure diferencia o "som" como tal do "som" como signo com recorrência, talvez para afastar-se das considerações que visavam apenas ao aspecto fisiológico, mas também para demarcar a necessidade de não se afastar por completo da materialidade - afinal, é a partir do aspecto concreto que é possível ao linguista (ou aos próprios sujeitos falantes) delimitar as unidades da língua. Eis a naturez̧a do objeto em linguística: não há um objeto dado, mas um fato linguístico:

Une succession de sons vocaux, par example mer $(\mathrm{m}+\mathrm{e}+\mathrm{r})$ est peutêtre une entité rentrant dans le domaine de l'acoustique, ou de la physiologie; elle n'est à aucun titre, dans cet état, une entité linguistique.

\footnotetext{
9 "Existe na língua: $1^{\circ}$ Se for considerada em um momento dado: não apenas signos, mas também significacõoes não separáveis dos signos, visto que estes não mereceriam mais seu nome sem a significação" (SAUSSURE, 2004, p. 67).

10 “a) as significações, as ideias, as categorias gramaticais fora dos signos [...] b) as figuras vocais que sevem de signos não existem mais na língua instantânea. Elas existem, então, para o físico, para o fisiologista, não para o linguista e nem para o sujeito falante. Assim como não há significação fora do signo $a$, assim também não há signo fora da significação" (SAUSSURE, 2004, p. 67).

11 " $2^{\circ} \mathrm{Se}$, ao contrário, a língua for considerada ao longo de um período: Então, não existe mais signo nem significação, mas apenas figuras vocais” (SAUSSURE, 2004, p. 68).
} 
Une langue existe si à $m+e+r$ s'attache une idée (SAUSSURE, 2011, p. $83-84)^{12}$.

Encarar as unidades linguísticas como "dados" é atribuir à língua recortes a priori, ignorando o lugar que o sujeito falante ocupa na sistemática da língua. Afinal, como já líamos no próprio Curso, só existe linguisticamente aquilo que é real para os sujeitos falantes de determinada língua.

Pensar a natureza da unidade linguística perpassa, assim, a reflexão acerca da dupla essência da linguagem. Afinal, do que se trata esta "dupla essência"? Qual a relevância desta discussão para a linguística? Sigamos o raciocínio do linguista genebrino:

Le dualisme profond qui partage le langage ne réside pas dans le dualisme du son et de l'idée, du phénomène vocal e du phénomène mental; c'est là la façon facile et pernicieuse de le concevoir. Ce dualisme réside dans la dualité du phénomène vocal COMME TEL, et du phénomène vocal COMME SIGNE - du fait physique (objectif) et du fait physico-mental (subjectif), nullement du fait «physique» du son par opposition au fait «mental» de la signification. Il y a un premier domaine, intérieur, psychique, où existe le signe autant que la signification, l'un idissolublement lié à l'autre; il y en un second, extérieur, où n'existe plus que le «signe»; mais à cet instant le signe réduit à une succession d'ondes sonores ne mérite pour nous que le nom de figure vocale (SAUSSURE, 2011, p. 86-87) ${ }^{13}$.

A passagem acima é fundamental para a nossa compreensão acerca da dupla essência da linguagem. A dupla essência da linguagem reside na dualidade entre o fenômeno vocal como tal (som fora do signo) e do fenômeno vocal como signo. Temos, assim, o aspecto material como necessário à essência da linguagem, associado ao fato subjetivo que é a associação entre o significado e o significante (a forma-sentido), imprescindível para que possamos falar de signo na sua concepção contemporânea. No que não consiste esse dualismo? Nem na oposição som X ideia, nem na oposição do vocal X mental.

\footnotetext{
12 "Uma sucessão de sons vocais, por exemplo mer $(\mathrm{m}+\mathrm{e}+\mathrm{r})$ é, talvez, uma entidade que regressa ao domínio da acústica, ou da fisiologia; ela não é, de jeito nenhum, nesse estado, uma entidade linguística. Uma língua existe se, à $m+e+r$, se vincula uma ideia” (SAUSSURE, 2004, p. 23).

13 “O dualismo profundo que divide a linguagem não reside no dualismo do som e da ideia, do fenômeno vocal e do fenômeno mental; essa é a maneira fácil e perniciosa de concebê-lo. O dualismo reside na dualidade do fenômeno vocal COMO TAL e do fenômeno vocal COMO SIGNO - do fato físico (objetivo) e do fato físico-mental (subjetivo), de maneira alguma do fato 'físico' do som por oposição ao fato 'mental' da significação. Há um primeiro domínio, interior, psíquico, onde existe o signo assim como a significação, um indissoluvelmente ligado ao outro; há um segundo, exterior, onde existe apenas o 'signo' mas, nesse momento, o signo se reduz a uma sucessão de ondas sonoras que merece de nós apenas o nome de figura vocal" (SAUSSURE, 2004, p. 24).
} 
Quais as implicações de refletirmos sobre a dupla essência da linguagem? Seria uma contradição falarmos do aspecto material em linguística? Afinal, lemos em diversas passagens que a figura vocal por si só não interessa ao linguista, mas ao fisiologista. Acreditamos que sim, cabe a nós, estudiosos da área, refletirmos mais profundamente sobre as implicações metodológicas acarretadas no momento em que vislumbramos que a língua não é só abstração. Conforme lemos em Milano (2017, p. 92), considerar os aspectos concreto e abstrato "constitue un chemin puissant qui nous oblige à faire face aux impasses que le maître genevois a dû gérer" ${ }^{\prime 14}$. Atentar-se ao aspecto material, concreto, do fenômeno da linguagem não significa afastar-se da linguística. Afinal, a existência da língua (a sua própria percepção) depende da sua realização na cadeia falada ${ }^{15}$.

Em linguística, tudo é uma questão de ponto de vista - "il n'y a pas la moindre trace de fait linguistique, pas la moindre possibilité d'apercevoir ou de déterminer un fait linguistique hors de l'adoption préalable d'un point de vue" (SAUSSURE, 2011, p. 93) ${ }^{16}$. É preciso, assim, sempre estarmos atentos ao método pelo qual pretendemos olhar para a língua. Ao refletirmos sobre a figura vocal, é inevitável abordar esta questão. Saussure destaca:

Ansi bien des linguistes pensent s'être placés sur le terrain physiologicoacoustique en faisant abstraction du sens du mot pour en considérer les éléments vocaux en disant que le mot champ au point de vue vocal est identique au mot chant; en disant que le mot comporte une partie vocale qu'on va considérer, plus une autre partie... etc. Mais d'où prend-on d'abord qu'il y a un mot, lequel devra être considérer ensuite à différents point de vue, car il m'est impossible de voir que le mot, au milieu de tous les usages qu'on en fait, soit quelque chose de donné, et qui s'impose à moi comme la perception d'une couleur (SAUSSURE, 2011, p. 91-92) ${ }^{17}$.

Quando dizemos que uma palavra é acusticamente idêntica a outra já saímos do terreno da fisiologia e adentramos no terreno da morfologia - ou seja, no âmbito da

14 "Constitui um caminho poderoso que nos obriga a encarar os impasses que o mestre genebrino teve que enfrentar” (MILANO, 2017, p. 92. Tradução livre).

15 A complexidade da relação entre os aspectos concreto e abstrato na delimitação das unidades linguísticas é discutida mais detalhadamente no artigo "Sobre objeto e método: do CLG ao manuscrito Phonétique" (STAWINSKI; MILANO, 2017).

16 "Não há o menor traço de fato linguístico, nem a menor possibilidade de perceber ou de determinar um fato linguístico fora da adoção anterior de um ponto de vista" (SAUSSURE, 2004, p. 27).

17 “Assim, muitos linguistas pensam ter se situado no terreno psicológico-acústico ao fazer abstração do sentido da palavra para considerar seus elementos vocais, dizendo que a palavra champ, do ponto de vista vocal, é idêntico à palavra chant, dizendo que a palavra comporta uma parte vocal que se vai considerar, mais uma outra parte, etc. Mas de onde se supõe, antes de tudo, que há uma palavra, que deverá ser considerada, depois, de diferentes pontos de vista? Só se obtém essa ideia, ela mesma, de um determinado ponto de vista, porque, para mim, é impossível ver que a palavra, em meio a todos os usos que dela se faz, seja algo dado, que se imponha a mim como a percepção de uma cor" (SAUSSURE, 2004, p. 26-27). 
consideração da forma em geral. A questão não é simplesmente o aspecto vocal, mas o valor que pode ser atribuído à materialidade. O ponto de vista não é vocal, é linguístico. Sendo assim, tudo que diz respeito à consideração morfológica equipara-se aos pontos de vista sincrônico, semiológico, gramatical e ao ponto de vista dos elementos na cadeia falada (elementos combinados, e não isolados), conforme anotações de Saussure. Do outro lado, teremos o ponto de vista diacrônico, "Non différent du point de vue phonétique (ou de la figure vocale dégagé de l'idée et dégagé de la fonction de signe [...]) (SAUSSURE, 2011, p. 94) ${ }^{18}$. Para o linguista,

Qui dit signe dit signification; qui dit signification dit signe; prendre pour base le signe (seul) n'est pas seulement inexact mais ne veut absolument rien dire, puisqu'à l'instant où le signe perd la totalité des significations, il n'est rien qu'une figure vocale (SAUSSURE, 2011, p. 101) ${ }^{19}$.

Nesse sentido, Saussure destaca três domínios no manuscrito: (I) o domínio não linguístico do pensamento puro, ou seja, fora do signo vocal e de toda a materialidade possível; (II) o domínio linguístico do signo vocallo: "Ce domaine est à la fois celui de la pensée relative, de la figure vocale relative, et de la relation entre ces deux" (SAUSSURE, 2011, p. 101 ${ }^{21}$; (III) o domínio linguístico do som puro, ou seja, o som por si só “considérée en luimême et hors de toute relation avec la pensée = PHONÉTIQUE” (SAUSSURE, 2011, p. $102)^{22}$.

O primeiro domínio, por ser considerado não linguístico, é aquele da massa amorfa de pensamento (e por isso não cabe ao linguista falar a partir deste domínio); o segundo domínio diz respeito à concepção de signo linguístico per se, à forma-sentido que existe apenas como tal na associação de seus elementos; já o terceiro domínio seria aquele da figura vocal pura - ultrapassando a compreensão de que o sistema é puramente abstrato, já que para que o

\footnotetext{
18 "Não difere do ponto de vista fonético (ou da figura vocal separada da ideia e separada da função de signo [...])" (SAUSSURE, 2004, p. 24).

19 "Quem diz signo diz significação; quem diz significação diz signo; tomar por base o signo (sozinho) não é apenas inexato, mas não quer dizer absolutamente nada porque, no instante em que o signo perde a totalidade de suas significações, ele nada mais é do que uma figura vocal" (SAUSSURE, 2004, p. 44).

${ }^{20}$ Para nós, a utilização de "signe vocal" em detrimento de "figure vocale" é distintiva, no sentido de que "figure vocale" é a pura materialidade enquanto que "signe vocal" pode ser compreendido como a materialidade que possui valor dentro de um sistema. Nossa compreensão baseia-se na própria passagem, que destaca que o "signe vocale" seria a "figure vocal" relativa, lançando mão, inclusive, da caracterização "signe vocal (sémiologie)".

21 "Esse domínio é, ao mesmo tempo, o do pensamento relativo, da figura vocal relativa e da relação entre os dois" (SAUSSURE, 2004, p. 43).

22 "Considerado em si mesmo e fora de qualquer relação com o pensamento = FONÉTICA" (SAUSSURE, 2004, p. 43).
} 
signo seja apreendido, para que ele mude, se transforme e se desenvolva é imprescindível que haja um aspecto material que merece ser apontado.

Eis a distinção fundamental para Saussure com relação à abordagem linguística:

La distinction fondamentale et unique en linguistique dépend donc de savoir: Si on considère un signe ou une figure vocale comme signe [...], ou si on considère un signe ou une figure vocale comme figure vocale; (...) parce qu'à chaque moment de son existence il n'EXISTE linguistiquement que ce qui est aperçu par la conscience, c'est-à-dire ce qui est ou devient signe (...) (SAUSSURE, 2011, p. 102-103) ${ }^{23}$.

A questão de saber sob qual ponto de vista encarar a materialidade é de suma importância para determinar como encaramos a língua: o que importará ao linguista será a realização sonora ou os efeitos que esta realização é capaz de produzir na cadeia discursiva? Acreditamos que era imprescindível para Saussure encarar esta questão, sob pena de que os estudos do linguista ficassem estagnados em uma concepção diacrônica (estudo da mudança do som ao longo do tempo) ou acrônica (estudo da produção sonora do aparelho fonador). Por isso, Saussure ainda diferencia, do terceiro domínio, o que chama de "Domaine physiologico-acoustique (non linguistique) de la figure vocale (s'imposant comme égale à elle-même em dehors de toute langue)" (SAUSSURE, 2011, p. 103) 24. É o puro som fora de qualquer relação com outros elementos sonoros - o som por ele mesmo e que não possui identidade ou diferença com qualquer outro elemento. É o som sem identidade, que não produz diferença. Para Saussure, esta última forma de abordar o som não interessa ao linguista.

A noção de diferença revela-se, na reflexão de Saussure, como um importante elemento para que se desenvolva uma concepção de sistema linguístico, diretamente ligada à ideia de relação: “tout l'objet sur lequel porte la science du langage est précipité dans une sphère de relativité" (SAUSSURE, 2011, p. 109) ${ }^{25}$. Por vezes, no entanto, vê-se que os elementos são tomados fora de qualquer relação com outros elementos da língua. É o que acontece quando se busca definir uma palavra isoladamente.

\footnotetext{
23 "A distinção fundamental e única, em linguística, depende, então, de saber: - se é considerado um signo ou uma figura vocal como signo (...); - ou se é considerado um signo ou figura vocal como figura vocal; (...) porque, a cada momento de sua existência, só EXISTE linguisticamente o que é percebido pela consciência, ou seja, o que é ou se torna signo" (SAUSSURE, 2004, p. 44).

24 "Domínio fisiológico-acústico (não linguístico) da figura vocal (que se impõe como igual a si mesma, independentemente de toda língua)" (SAUSSURE, 2004, p. 28).

25 "Todo objeto sobre o qual incide a ciência da linguagem é precipitado numa esfera de relatividade" (SAUSSURE, 2004, p. 62).
} 
Saussure aponta que há na linguística, infelizmente (malheuresement) (SAUSSURE, 2011, p. 109), três maneiras diferentes de representar a palavra: (I) a palavra representada totalmente fora de nós, como no caso da palavra que faz parte de um dicionário, sendo esta considerada a sua existência; (II) a palavra entendida como, igualmente, estando fora de nós, havendo duas partes: a física (material) que seria a palavra, e seu sentido (mental, abstrato); (III) finalmente, a última maneira é a de encarar a palavra como existente apenas a partir da consciência que temos ou podemos tomar a partir dela, assim como a de seu sentido:

Un mot n'existe véritablement, et à quelque point de vue qu'on se place, que par la sanction qu'il reçoit de moment en moment de ceux qui l'emploient. C'est ce qui fait qu'il diffère d'une succession de sons, et qu'il diffère d'un autre mot, fût-il composé de la même succession de sons (SAUSSURE, 2011, p. 112) ${ }^{26}$.

Assim, falar sobre a materialidade demanda a discussão sobre a própria definição de palavra, já que há palavras que são idênticas na sua realização vocal, mas que mesmo assim diferenciam-se em identidade e valor. No centro desta reflexão está a concepção de diferença, essencial para que possamos falar de sistema linguístico. O que importa que chant e champ sejam idênticos na figura vocal? Ambos são percebidos como duas unidades distintas na percepção da cadeia discursiva. O que atesta a existência de duas palavras distintas apesar da sua equivalência sonora não é a sua materialidade, mas a consciência de que existem, linguisticamente, duas unidades distintas.

Quando Ferdinand de Saussure se vale da comparação dos elementos químicos tomados isoladamente ou em combinação, o linguista destaca outra questão bastante importante: a dualidade da palavra representa ou não a dualidade dos domínios físico e psicológico? Temos reiteradamente tentado mostrar que não. Saussure observa que

Les duex éléments de l'air sont dans l'ordre matériel, et les deux éléments du mot sont réciproquement dans l'ordre spirituel; notre point de vue constant sera de dire que non seulement la signification, mais aussi le signe est un fait de conscience pur (SAUSSURE, 2011, p. 116) ${ }^{27}$.

\footnotetext{
26 "Uma palavra só existe verdadeiramente, de qualquer ponto de vista que se adote, pela sanção que recebe, a cada momento, daqueles que a empregam. É isso que faz com que ela difira de uma sucessão de sons" (SAUSSURE, 2004, p. 76).

27 “Os dois elementos do ar estão na ordem material e os dois elementos da palavra estão, reciprocamente, na ordem espiritual; nosso ponto de vista constante será dizer que, não apenas a significação, mas também o signo, é um puro fato de consciência" (SAUSSURE, 2004, p. 22).
} 
Assim, não se trata de olhar para o aspecto material do signo para resumi-lo à pura substância. O que vale ressaltar é que a materialidade (concretude) do signo é necessária para que possamos compreender a língua como um sistema essencialmente abstrato, já que o sistema nada mais é do que o jogo de diferenças de valor entre determinados elementos, diferenças que precisam ser reconhecidas como significativas para um sujeito falante. Em suma, trata-se de atestar a importância da materialidade na medida em que é a partir deste aspecto que vemos ser impossível dissociar a língua dos sujeitos falantes. Como bem destacou Saussure:

Le fait par exemple que aka est prononcé par telle personne à un certain endroit et à un certain moment, ou le fait que mille personnes à milles endroits et à mille moments émettent la succession de sons aka est absolument le seul fait donné: mas il n'en est pas moin vrai que [seul] le fait ABSTRAIT < de> l'identité acoustique de ces aka, forme seul l'entité acoustique aka: et qu'il n'y a pas à chercher un objet premier plus tangible, que ce premier objet abstrait (SAUSSURE, 2011, p. 120)28.

A identidade (ou não identidade) apreendida pelos falantes de determinada língua reacende o debate sobre a natureza da "existência" da língua:

Où existe une composition musicale? C'est la même question que de savoir où existe aka. Réelement cette composition n'existe que quand on l'exécute; mais considérer cette exécution comme son existence est faux. Son existene, c'est l'identité des exécutions (SAUSSURE, 2011, p. 121) ${ }^{29}$.

A existência não está na concretude, na materialidade por si só (o que vincularia a existência da língua a sua representação ou reprodução). A existência da língua é vislumbrada na identidade, no valor operado pelas unidades na cadeia falada. Como bem aponta Milano, "la portion matérielle vaut plus pour produire des différences (et des oppositions) que parce qu'elle porte de la matérialité phonique en soi; le signifiant n'est donc pas le son" (MILANO, 2017, p. 88) ${ }^{30}$. A cadeia falada atesta o valor, reconhecido, a cada execução, por um sujeito falante. Esse reconhecimento só ocorrerá quando o que poderia ser meramente uma figura vocal é, na realidade, forma na língua:

\footnotetext{
28 "O fato, por exemplo, de aka ser pronunciada por uma pessoa, num certo lugar e num certo momento, ou o fato de mil pessoas, em mil lugares e em mil momentos, emitirem a sucessão de sons aka, é, absolutamente, o único fato dado: mas não é menos verdade que só o fato ABSTRATO, a identidade acústica desses aka, forma sozinho a entidade acústica aka: e que não há um objeto primeiro a ser procurado, mais tangível do que esse primeiro objeto abstrato" (SAUSSURE, 2004, p. 33).

29 “Onde é que existe uma composição musical? É a mesma questão de saber onde existe aka. Na verdade, essa composição só existe quando é executada; mas considerar essa execução como sua existência é falso. Sua existência é a identidade dessas execuções" (SAUSSURE, 2004, p. 33).

30 "A porção material vale mais por produzir diferenças (e oposições) do que pelo o que ela carrega de materialidade fônica em si; o significante não é, portanto, o som” (MILANO, 2017, p. 88. Tradução livre).
} 
- Une forme est une figure vocale qui est pour la conscience des sujets parlants déterminé, c'est-à-dire à la fois existante et délimitée. Elle n'est rien de plus; comme elle n'est rien de moins. Elle n'a pas nécessairement « un sens » précis; mais elle est ressentie comme quelque chose qui est; qui de plus ne serait plus, ou ne serait plus la même chose, si on changeait quoi que ce soit à son exacte configuration [

( Je doute qu'on puisse définir la forme par rapport à la figure vocale; il faut partir de la donnée sémiologique) (SAUSSURE, 2011, p. $131)^{31}$

$\mathrm{Na}$ passagem acima atesta-se claramente a distinção de forma em relação à figura vocal. A forma é a figura vocal que significa para o sujeito falante. Delimitada como significante, a figura vocal ultrapassa o terreno do "som puro" para o terreno da significação:

---- Une figure vocale devient une forme depuis l'instant où on l'introduit dans le jeu des signes appelé langue, de la même façon qu'un morceau d'étoffe dormant à fond de cale devient un signal à l'instant où il est hissé $1^{\circ}$ parmi d'autres signes hissés au même moment et concourant à une signification; $2^{\circ}$ entre cent autres qui auraient $p u$ être hissés (...) (SAUSSURE, 2011, p. 132) 32 .

Eis o significante linguístico: o signo vocal com a potência de significação entre outras formas linguísticas - aquilo que significa ou que pode significar na rede semiológica que é a língua: "Qui dit forme dit différence avec d'autres formes et ne dit rien d'autre" (SAUSSURE, 2011, p. 132) ${ }^{33}$. Só vale o que produz diferença na língua (ou seja, para o sujeito falante) - "On appelle forme une figure vocale qui est déterminée pour la conscience des sujets parlants" (SAUSSURE, 2011, p. 133) ${ }^{34}$.

O conceito de forma supera o de figura vocal e ajuda a diluir o que poderia ser compreendido como uma ligação direta entre a materialidade e o que esta representa no jogo dos signos. Saussure reitera: "Forme implique: DIFFÉRENCE: PLURALITÉ.

\footnotetext{
31 "Uma forma é uma figura vocal que, na consciência dos sujeitos falantes, é determinada, ou seja, é ao mesmo tempo existente e delimitada. Ela não é nada mais; assim como não é nada menos. Ela não tem, necessariamente, 'um sentido' preciso; mas ela é percebida como coisa que é; que, além disso, não seria mais, ou não seria mais a mesma coisa, caso se modifique o que quer que seja em sua exata configuração. (Eu duvido que se possa definir a forma com relação à "figura vocal', é preciso partir do dado semiológico)" (SAUSSURE, 2004, p. 37-38).

32 "Uma figura vocal se torna uma forma a partir do instante crucial em que é introduzida no jogo de signos que se chama língua, da mesma maneira que um pedaço de pano, jogado no fundo do navio, se torna um sinal no instante em que é içado $1^{\circ}$ entre outros signos içados no mesmo momento e que contribuem para a sua significação; $2^{\circ}$ entre cem outros que poderiam ser içados (...)" (SAUSSURE, 2004, p. 38).

33 "Quem diz forma diz diferença com outras formas e nada mais" (SAUSSURE, 2004, p. 47).

34 "Chama-se forma uma figura vocal que é determinada para a consciência dos sujeitos falantes" (SAUSSURE, 2004, p. 47).
} 
(SYSTÈME?). SIMULTANÉITÉ. VALEUR SIGNIFICATIVE”' (SAUSSURE, 2011, p. $138)^{35}$. Retomando a definição de figura vocal, o linguista reforça novamente:

Pour qu'une FORME soit, comme forme, et non comme figure vocale, il y a deux conditions constantes, quoique ces deux conditions se trouvent en dernière analyse n'en former qu'une seule: $1^{\circ}$ que cette forme ne soit pas séparée de son opposition avec d'autres formes simultanées [ $2^{\circ}$ que cette forme ne soit pas séparée de son sens : [ (SAUSSURE, 2011, p. $139)^{36}$.

Retornamos à problematização inicial deste artigo: apenas se considera forma o que está vinculado a um sentido e vice-versa. Linguisticamente, estes termos são inseparáveis são a frente e o verso da folha de papel: forma-sentido. Além de não existirem fora dessa relação, também não existem isoladamente, fora de um sistema, como destaca Saussure em outra passagem: “Toute l'étude d'une langue comme système, c'est-à-dire d'une morphologie, revient, comme on voudra, à l'étude de l'emploi des formes, ou à celle de la répresentation des idées" (SAUSSURE, 2011, p. 169-170) ${ }^{37}$. Cindir a relação forma-sentido é desfazer a sua própria natureza simbólica:

Admettre la forme hors de son emploi c'est tomber dans la figure vocale qui relève de la physiologie et de l'acoustique, c'est em outre plus immédiatement se mettre en contradiction avec soi-même car il y a beaucoup de formes identiques de son et qu'on ne songe même pas à rapprocher, ce qui est la meilleure preuve de l'inanité parfaite de l'être forme hors de son emploi (SAUSSURE, 2011, p. 170) ${ }^{38}$.

É possível vislumbrar, a partir de todas estas considerações, a preciosidade com que Saussure buscava considerar cada definição a qual julgava importante para a delimitação do objeto da linguística, cuja complexidade demandava detalhar pormenores exaustivamente. As inúmeras definições de forma e explanações a respeito da importância de considerar a unidade linguística na cadeia falada (ou seja, na relação com outros elementos do sistema, em presença ou em ausência) são prova da minúcia do genebrino. Na passagem a seguir,

\footnotetext{
35 "DIFERENÇA: PLURALIDADE [SISTEMA?]. SIMULTANEIDADE. VALOR SIGNIFICATIVO" (SAUSSURE, 2004, p. 36).

36 "Para que uma FORMA exista, como forma, e não como figura vocal, há duas condições constantes, embora, em última análise, essas duas condições acabem por formar uma só: $1^{\circ}$ que essa forma não seja separada de sua oposição com outras formas simultâneas; $2^{\circ}$ que essa forma não seja separada de seu sentido" (SAUSSURE, 2004, p. 31).

37 "Todo o estudo de uma língua como sistema, ou seja, de uma morfologia, se resume, como se preferir, no estudo do emprego das formas ou no da representação das ideias" (SAUSSURE, 2004, p. 32).

38 “Admitir a forma fora de seu emprego é cair na figura vocal que pertence à fisiologia e à acústica. É, além disso, mais imediatamente, entrar em contradição consigo mesmo porque há muitas formas idênticas de som e que nem se sonha em abordar, o que é a melhor prova da perfeita inanidade do ser forma fora de seu emprego" (SAUSSURE, 2004, p. 33).
} 
Saussure destaca a necessidade de se tomar o signo em relação com os elementos do sistema:

Comme le signe premier ne valait rien, si ce n'est par les signes ambiants, il est fort inutile de se demander comment ceux qui en procedent valent ceci, ne valent pas cela, et valent encore quelque chose alors qu'ils ont matériellement cessé d'exister - à moins de se décider à considérer tout le temps les signes ambiants qui seuls déterminent en effet la valeur et l'existence même de chaque signe: seulement, considérer cet entourage, c'est rompre franchement avec la phonétique, c'est se soumettre à entrer dans le monde des signes comme choses signifiantes, uniquement comme choses signifiantes, et présentes à la conscience; par consequence, à ignorer systématiquement toutes circonstances étymologiques ou rétrospectives: lesquelles sont absentes de la conscience (SAUSSURE, 2011, p. 174-175) ${ }^{39}$.

Em suma, o signo isolado nada vale, e considerá-lo no seio do sistema linguístico é passar ao ponto de vista sincrônico - é romper, conforme as próprias palavras do mestre com a fonética (estudo diacrônico), passando a importar essencialmente o signo na sua função significante, responsável por produzir efeitos de identidade e valor na consciência dos sujeitos falantes de determinada língua. Resta, assim, deste ponto de vista, deixar por um momento de lado as considerações que fujam à percepção dos falantes deste sistema visto que, como vimos anteriormente, só existe linguisticamente aquilo que é real para os sujeitos falantes de tal sistema sincrônico.

\section{Considerações finais}

As questões apontadas até aqui visam salientar a importância da reflexão acerca da natureza material e significante da língua, além de apontar uma possível interpretação acerca do que seria a dupla essência da linguagem, entendida aqui como a oposição da figura vocal (som como tal) e da forma-sentido (som como signo). Ademais, buscamos destacar os conceitos de valor e de sistema aliados à percepção e consciência dos sujeitos falantes das unidades linguísticas.

\footnotetext{
39 “Como o signo primeiro não valeria nada, se não fosse pelos signos ambientes, é inútil se perguntar como os que dele procedem valem isto, não valem aquilo e valem, mesmo, alguma coisa embora, materialmente, tenham deixado de existir - a menos que se decida considerar os signos ambientes que, sozinhos, determinam, com efeito, o valor e a própria existência de cada signo: considerar apenas esse entourage é romper francamente com a fonética, é se submeter a entrar no mundo dos signos como coisas significantes e presentes na consciência; por conseguinte, a ignorar sistematicamente todas as circunstâncias etimológicas e retrospectivas, que estão ausentes da consciência” (SAUSSURE, 2004, p. 63-64).
} 
Em suma, o som como figura vocal é a materialidade necessária para que a língua tenha existência. Como mera figura vocal ela interessa apenas ao fisiologista, mas quando ultrapassa o estatuto da materialidade para adentrar à esfera da significação (abstração) estamos já considerando o seu valor em um sistema linguístico - ou seja, em um valor que produz efeitos para o sujeito falante de um sistema linguístico. Sendo assim, a figura vocal representa o aspecto material necessário a todo o sistema semiológico - sem ser posta em oposição com um "sentido" ou "significado", mas sim à própria materialidade que é significante.

O ponto de chegada da concepção de "som" como signo parece ser justamente este: o do conceito de significante linguístico, visto que é a partir daí que é possível vislumbrar que, para muito além do aspecto material, há efeitos de identidade, diferença e valor, os quais são percebidos por um sujeito falante de determinada língua. Acreditamos que a dupla essência da linguagem - vista como esta complexa oposição entre o som como tal e o som como signo tenha ecoado em inúmeras considerações metodológicas e epistemológicas realizadas pelo mestre genebrino. O resgate desta problematização talvez ainda tenha efeitos a produzir no que concerne não somente aos estudos saussurianos em geral, mas à linguística, convocada a uma perspectiva que realce o papel que corpo e que a percepşão tem a desempenhar no nosso entendimento sobre língua e linguagem.

\section{Referências}

AMACKER, R. Avant-propos. In: SAUSSURE Science du Langage: de la double essence du langage et autres documents du ms. BGE Arch. De Saussure 372. Édition Critique établie par René Amacker. Genève: Librarie Droz, 2011.

FRYDRYCH, L. O estatuto linguístico das línguas de sinais: a Libras sob a ótica saussuriana. Dissertação (Mestrado em Teorias do Texto e do Discurso). Porto Alegre: Universidade Federal do Rio Grande do Sul, 2013.

MILANO, L. Le statut du phonique dans le CLG. Cahiers Ferdinand de Saussure, v. 70. Genève: Droz, 2017, p. 85-100.

SAUSSURE, F. de. Escrits de linguistique générale. Etablis et édités par Simon Bouquet et Rudolf Engler avec la collaboration d'Antoinette Weil. Paris: Gallimard, 2002.

Escritos de Linguística Geral. Organizado por Simon Bouquet e Rudolf Engler. São Paulo: Cultrix, 2004. 
Science du Langage: de la double essence du langage et autres documents du ms. BGE Arch. De Saussure 372. Édition Critique établie par René Amacker. Genève: Librarie Droz, 2011.

STAWINSKI, A.; MILANO, L. Sobre objeto e método: do CLG ao manuscrito Phonétique. Gragoatá, v. 22, nº 44, p. 1172-1183, set./dez. 2017.

\begin{abstract}
This article intends to discuss what the dual essence reiterated by linguist Ferdinand de Saussure refers to, based on the set of manuscripts titled De la double essence du langage. We will thus use the interpretation of the critical edition organized by Amacker (SAUSSURE, 2011), raising the following questions: what is essential for a linguistic system to exist? Is material data relevant to the construction of the linguistic fact? What is the difference between considering the "sound" as a vocal figure and "sound" as a sign? We chose to start from the occurrences of "vocal figure" in Saussure's considerations in order to more comprehensively understand the role of the vocal figure and its relation to the concept of form. The questioning of these notions enables the reflection on the indissoluble link between form and meaning in Saussurean studies and highlights the important role of the material aspect linked to its significant function.
\end{abstract}

Keywords: Vocal figure. Sign. Form. Dual essence

Recebido em: 29/04/2018.

Aceito em: 10/05/2018. 